\title{
Molecular mechanisms of photosensitization induced by drugs XIV: Two different behaviours in the photo- chemistry and photosensitization of antibacterials containing a fluoroquinolone like chromophore
}

\author{
G. De Guidi, ${ }^{1 \dagger}$ S. Giuffrida, ${ }^{1}$ S. Monti, ${ }^{2}$ P. S. Pisu, ${ }^{1}$ \\ S. Sortino, ${ }^{1}$ and L. L. Costanzo ${ }^{1}$ \\ ${ }^{1}$ Dipartimento di Scienze Chimiche Università di Catania, Viale A.Doria 8, 95125 Catania, Italy \\ ${ }^{2}$ Istituto di Fotochimica e Radiazioni d'Alta Energia del CNR, Area della Ricerca, \\ Via P.Gobetti 101, 40129 Bologna, Italy
}

\begin{abstract}
This paper deals with the photosensitizing activity of FLQs towards two different biosubstrates, membrane and DNA. The in vitro phototoxic activity of these drugs vs. DNA presents peculiar features with respect to that $v s$. membranes, probably due to a specific binding of the drugs to the double helix and to the operativeness of different photosensitization mechanisms with the two types of biosubstrates. A description of the UVA photochemistry and the photosensitizing properties of two significant examples in the FLQ family is reported. The investigated compounds are Enoxacin, 1-ethyl-6-fluoro-1,4-dihydro-4oxo-7-[1-piperazinyl]-1,8-naphtyridine-3-carboxilic acid and Rufloxacin, 9-fluoro-2,3-dihydro-10-4' -methyl1'-piperazinyl-7-oxo-7H-pyrido[1,2,3-de]-1,4-benzothiazine-6-carboxylic acid.
\end{abstract}

\section{INTRODUCTION}

Great interest has been recently shown in the mechanisms of degradation of drugs belonging to the pharmacological class of antibacterial fluoroquinolones (FLQ), which are widely used in the clinical practice as broad spectrum antimicrobial agents [1]. These compounds develop their pharmacological action via the specific inhibition of the subunit-A of the bacterial topoisomerase DNA girase, which controls the shape of DNA [2]. Particular attention was devoted to the light induced degradation of FLQs, as proven by several reports dealing with adverse cutaneous reactions and in vitro phototoxicity through photosensitization under UVA irradiation [3-11]. In addition, even photocarcinogenic consequences were reported [12-14]. A few contributions appeared up to now about the photochemical and photophysical properties of these compounds [15-19]. Here we want to summarize the photosensitizing activity of a series of FLQs towards two different kinds of biosubstrates, membrane and DNA, and then to show two significant examples in this molecular family as regards both photochemistry and photosensitization properties for UVA irradiation in aqueous buffered solutions. These compounds are Enoxacin, 1-ethyl-6-fluoro-1,4-dihydro4 - oxo-7- [1-piperazinyl] -1, 8-naphtyridine-3-carboxilic acid (ENX) and Rufloxacin (RFX), 9-fluoro-2,3-dihydro10-4' -methyl-1' -piperazinyl-7-oxo-7H-pyrido[1,2,3-de]1,4-benzothiazine-6-carboxylic acid (see Scheme 1).

\section{MATERIALS AND METHODS}

Reagents. Enoxacin (ENX), Norfloxacin (NFX), Ofloxacin

† gdeguidi@dipchi.unict.it<smiles>CCn1cc(C(=O)O)c(=O)c2cc(F)c(N3CCNCC3)nc21</smiles>

ENOXACIN<smiles>CCOC#N</smiles>

Scheme 1

(OFX) and phosphatidylcholine from egg yolk, were purchased from Sigma Chemical Co (St. Louis MO, USA). Clinafloxacin (CLX) was a gift from Parke-Davis (Ann Arbor MI USA) Ciprofloxacin (CPX) was a gift from Miles (Bayer) (Kankakee IL USA). Fleroxacin (FLX) was a gift from Hoffmann La Roche (Basel Switzerland). Lomefloxacin (LMX) was a gift from Searle (Peschiera Borromeo, Milano Italy). Orbifloxacin (ORX) was a gift from Dainippon (Osaka, Japan). Pefloxacin (PFX) was a gift from Rhône Poulenc (Rorer Milano Italy). Rufloxacin (RFX) was a gift from Bracco and Mediolanum (Milano, Italy). Sparfloxacin (SPX) was from Zagam pills produced by Rhône Poulenc Rorer (Antony-France). All other chemicals were reagent grade. Phosphate buffer saline (PBS) ( $\mathrm{pH} 7.4$ ) consisted of a $10 \mathrm{mM}$ phosphate buffer solution added with either $0.135 \mathrm{M}$ or $5 \times 10^{-2} \mathrm{M}$ 
$\mathrm{NaCl}$ for membrane or DNA experiments respectively. Supercoiled pBR322 DNA (sc-DNA), form I, MW $2.9 \times$ $10^{6} \mathrm{D}, 4365$ base pairs (bp) and sonicated calf thymus DNA (ct-DNA) (phenol extracted, lyophilised, average size 2,000 bases, range 200-6,000 bases) were obtained from Pharmacia (Milano, Italy). The percentage of relaxed form II of pBR322 was less than 12\% in the starting material and no linear form III was detected (the data were obtained from densitometric analysis of agarose gel electrophoresis).

Irradiation conditions. In all the photosensitization experiments, the irradiation was performed using a Rayonet photochemical reactor equipped with 8 "black light" phosphor lamps with an emission in the 310-390 nm range with a maximum at $350 \mathrm{~nm}$. The fluence rate at the irradiation position was about $800 \mu \mathrm{W} / \mathrm{cm}^{2}$. The incident photon flux on either $3 \mathrm{~mL}$ solution in quartz cuvettes (optical length, $1 \mathrm{~cm}$ ) (photohemolysis and photoperoxidation experiments) or on a $18 \mu \mathrm{L}$ solution in the Eppendorf tubes $(0.2 \mathrm{~cm}$ of optical path) (DNA experiments), was $6 \times 10^{16}$ and $2.8 \times 10^{15}$ quanta $\mathrm{s}^{-1}$ respectively. A "merry-go-round" irradiation apparatus was used to ensure that all the samples received equal radiation doses. Monochromatic irradiation at $325 \mathrm{~nm}$ was obtained by using a He-Cd laser (series 200, Liconix St. Clara CA, USA). The experimental procedures for irradiation and the light intensity measurements are described in [11] and in the literature there cited.

Hemolysis assays. Red blood cells (RBCs) were prepared by washing, in PBS, samples of out-of-date (no more than 15 days from the date stated) packed human erythrocytes, supplied by the local blood bank. Each series of tests was performed with aliquots from the same sample of blood.

Photohemolysis experiments were carried out in PBS by measuring the decrease in absorbance at $650 \mathrm{~nm}$. For additional details $c f$. [11].

Liposomes preparation and lipid peroxidation. Unilamellar liposomes of phosphatidylcholine from egg yolk were prepared with the solvent injection method. Lipid peroxidation was measured spectrophotometrically by the thiobarbituric acid (TBA) assay. The formation of TBA reactive substances (TBARS) was assumed as the degree of peroxidation. Other details appear in [11] and literature there cited.

DNA photocleavage experiments. The samples containing pBR322 DNA and sensitizer were prepared in a final volume of $18 \mu \mathrm{L}$, placed in Eppendorf tubes and irradiated in a Rayonet photochemical reactor. The electrophoretic analysis was performed in $1 \%$ agarose gel and DNA forms were detected by excitation of ethidium bromide fluorescence. Quantitation of bands was achieved by microdensitometry of the negative produced from the gel photograph. In our photocleavage experiments no more than $10 \%$ Form III DNA was produced.

Time resolved measurements. Transient absorption spectra were obtained by a nanosecond laser flash photolysis apparatus based on a Nd-YAG laser (JK Lasers, pulse $20 \mathrm{~ns}$ FWHM, $355 \mathrm{~nm}$ ). The laser beam was focused on a $3 \mathrm{~mm}$ high and $10 \mathrm{~mm}$ wide rectangular area of the cell and the first $2 \mathrm{~mm}$ were analysed at a right angle geometry. The energy used was $\leq 4 \mathrm{~mJ} /$ pulse. Spectral resolution was $2 \mathrm{~nm}$. Luminescence lifetimes were obtained by means of an IBH single-photon-counting apparatus $\left(\mathrm{N}_{2}\right.$ lamp, excitation at $\left.337 \mathrm{~nm}\right)$ with subnanosecond resolution. See [19] for further details.

\section{GENERAL SCREENING}

The absorption spectra of FLQs in phosphate buffered saline ( $\mathrm{pH}$ 7.4) are characterised by relatively intense absorption bands in the UVA region with a tail extending, in some cases, beyond $400 \mathrm{~nm}$. These spectral features indicate that these drugs have the potential to behave as efficient UVA sensitizers. A screening of the photosensitizing activity of a series of compounds of this family toward membranes and DNA shows that photoinduced damage proceeds through different mechanisms depending on the target involved. In fact, as shown in Figure $1 \mathrm{~A}$ and $1 \mathrm{~B}$, the relative efficiency of the membrane photoinduced damage follows an order which is completely different from that observed for DNA induced damage. In Figure $1 \mathrm{~A}$ we can identify a scale of induced phototoxicity in red blood cells, by considering the time needed to reach the $50 \%$ of membrane disruption, $t_{50}$, after irradiation in the presence of the drug [11]. This scale of activity starts from Rufloxacin, which displays the higher photodamaging action, to drop down to Clinafloxacin, which appears to be the less efficient as regards this biological target. Each drug is used at a different concentration, to have the same dose of absorbed radiation $D$. The dose (in micromoles of photons) equals the product $F \times I \times t$, where $I$ is the light intensity at the irradiation wavelength (micromoles of photons $\left.\mathrm{min}^{-1}\right) t$ is the irradiation time in minutes and $F=\left(1-10^{-A}\right)$ is the fraction of light absorbed by the fluoroquinolone. All the used concentrations are in the range of those attained in the blood serum after therapeutic administration. Further details about membrane targeting can be obtained from lipid peroxidation studies in small unilamellar liposomes, which represent a simpler model compared with erythrocyte membrane, but give useful information both on the role of single membrane components in the photosensitized damage and on the importance of the damage with respect to cell resistance. In the same Figure $1 \mathrm{~A}$ we compare the photohemolytic activity of fluoroquinolones with their ability to induce lipid peroxidation, estimated as the amount of photoproduced species, reactive toward the thiobarbituric acid [20]. The trend observed shows that, the higher is the degree of photoinduced peroxidation, the lower is the time needed to reach 50\% hemolysis and, consequently, the cell resistance. These results strongly support a tight connection between photosensitized membrane damage (at least as regards the RBC model) and lipid photoperoxidation. In Figure $1 \mathrm{~B}$ the DNA photoinduced damage for the same series of FLQs 

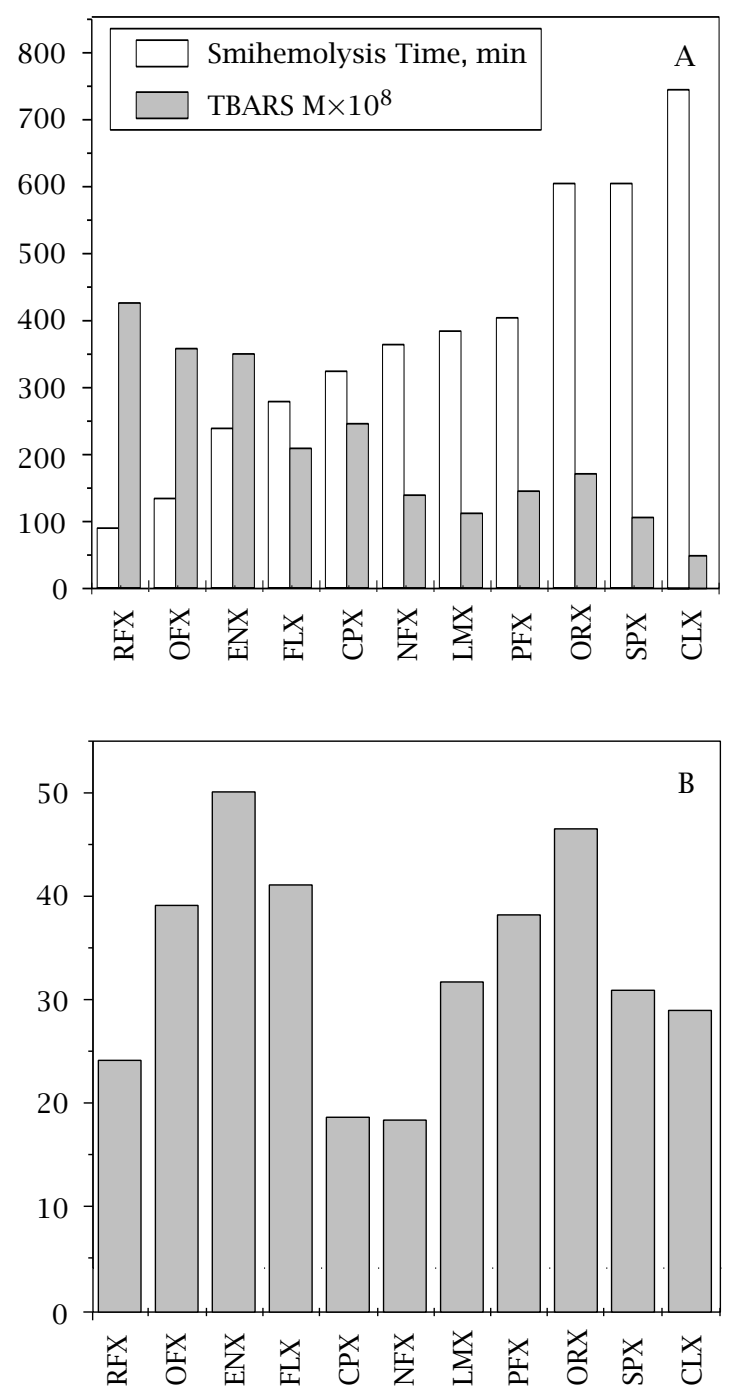

Figure 1. A Photosensitizing activity of Fluoroquinolones towards red blood cells and unilamellar liposomes in PBS $\mathrm{pH}=7.4$ (doses $=235$ and $400 \mu \mathrm{mol}$ of photons respectively). Data reported represents the means of three experiments $(\mathrm{SD}=10 \%)$; $\%$ DNA photocleavage induced by the same fluoroquinolones; [pBR322 $]_{\mathrm{bp}}=33 \mu \mathrm{M}$ in PBS $\mathrm{pH}=$ 7.4 (dose $=0.41 \mu \mathrm{mol}$ of photons). Data reported represents the means of three experiments $(\mathrm{SD}=10 \%) . T=25^{\circ} \mathrm{C}$.

is reported. The study of DNA models in the investigation of fluoroquinolone-mediated biological photosensitization is particularly important because, as mentioned above, the pharmacological action of these drugs affects the bacterial DNA replication, recombination and repair. Like in experiments on membranes, fluoroquinolones are tested with DNA at the same absorbed dose. Photoinduced DNA cleavage is determined by measuring the degree of linearization of a supercoiled plasmid. The conformation of supercoiled form I of DNA is in fact firstly converted in relaxed open circular form II via single strand break and finally to linear form III through double strand break [11]. As it was mentioned above the scale of activity does not follow the order observed for membranes. This is likely due both to a specific binding of these drugs to the double helix, a substrate quite different from the cell membrane bilayer, and, to a different mechanism of photosensitization of DNA with respect to membranes. In the following an example consistent with this conclusion is described.

\section{TWO DIFFERENT BEHAVIOURS: ENOXACIN AND RUFLOXACIN}

Enoxacin. This drug should not be considered strictly a FLQ, differing by the presence of the naphthyridine ring in place of the quinolone moiety. Spectroscopic and photochemical studies of ENX in water showed out that its photodegradation consists mainly in a defluorination by heterolytic $\mathrm{C}-\mathrm{F}$ bond fragmentation. This process is believed to involve a mesomeric carbocationic and carbene form as intermediate [18].

The spectroscopic properties of ENX are strongly influenced by $\mathrm{pH}$ because of the acid-base equilibria involving the 3-carboxyl and the 7-piperazinyl groups. The zwitterion, largely dominant at neutral $\mathrm{pH}$, is the form with the best fluorescence properties and the lowest photochemical stability, the loss of fluoride appearing favored both by dissociation of the carboxylic group and protonation of the piperazinyl residue. The involvement of the zwitterion in the phototoxic reactions induced by ENX in physiological conditions is highly probable. The role of the lowest triplet as photoactive state was evidenced. A further transient with $670 \mathrm{~nm}$ absorption maximum and submicrosecond lifetime was formed in phosphate buffer and assigned to the defluorination pathway Scheme 2 [19].

ENX acts as efficient photosensitizer towards several biological targets such as red blood cells, liposomes and DNA [11]. In the presence of oxygen, hydroxyl radicals, formed from $\mathrm{H}_{2} \mathrm{O}_{2}$ via the Fenton reaction, mainly mediate photosensitization in the membranes. Hydroxyl radicals are also involved in DNA cleavage, but the most harmful species responsible for the damage of this biosubstrate has been identified in the $670 \mathrm{~nm}$ intermediate generated by ENX photodefluorination [19]. This transient species, tentatively identified as the carbocation/carbene intermediate expected to be highly reactive with DNA [21,22] , exerts the highest damaging action in the absence of oxygen. The opposite effect of oxygen in photoinduced damage of membranes and DNA, activating in the first case, depressing in the second (see Table 1), provides a partial explanation for the different FLQ photosensitizing properties shown in Figure 1. On the other hand we cannot exclude that ground state association (via intercalation or surface binding), occurs to some extent in spite of the experimental evidences of this fact are not striking. In the associated species unquenchable reactions, such as photobinding or photodimerization, with unexpected damaging consequences could occur [11]. Neither singlet oxygen 


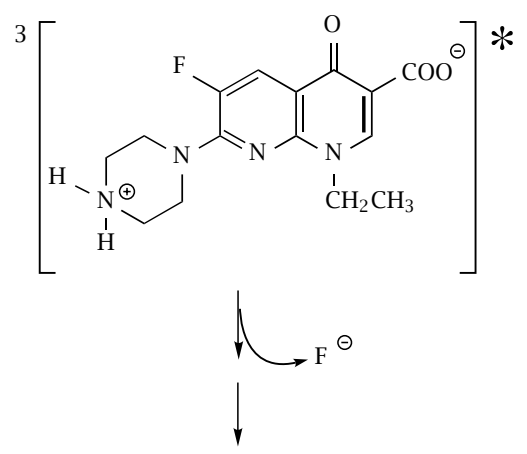

$\mathrm{RBC}=$ Red Blood Cells
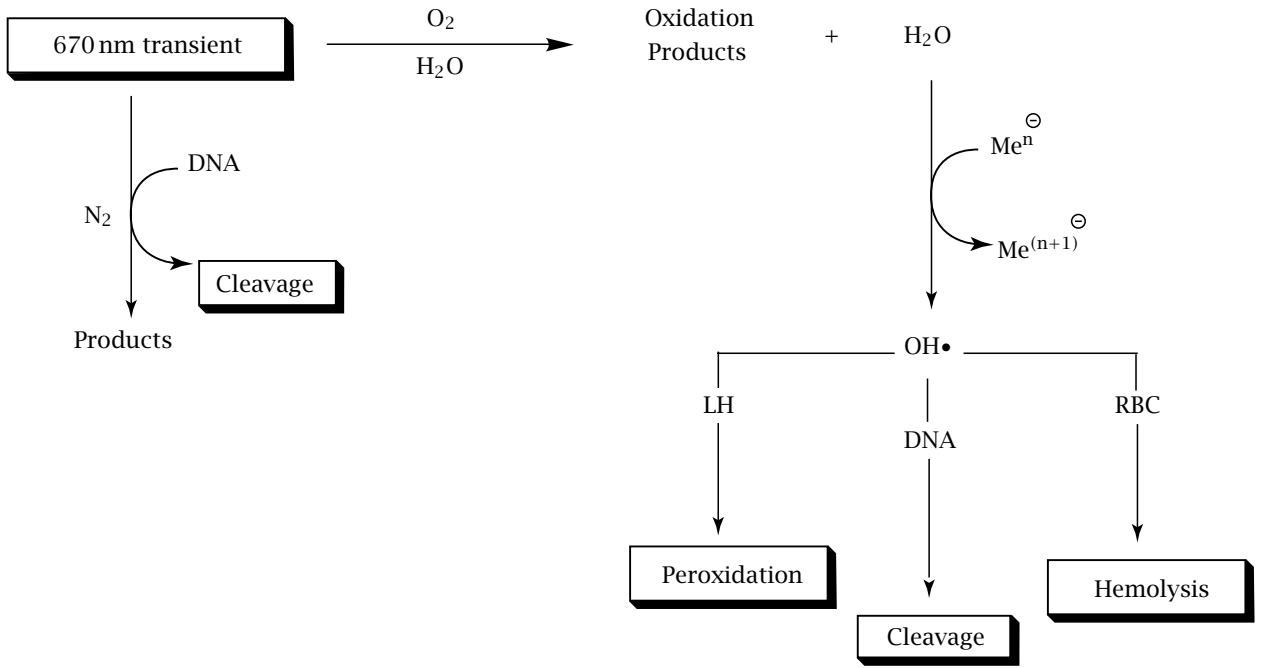

Scheme 2. Enoxacin photosensitization pathway.

nor lytic photoproducts seem to be involved in the ENX induced photosensitization processes $[11,19]$.

Rufloxacin. The operativeness of a type II photosensitization mechanism involving singlet oxygen-mediated photodamage, represents one of the main differences with respect to ENX. Important differences are in fact observed in the RFX photochemistry and photophysics. ${ }^{19} \mathrm{~F}$ NMR spectroscopy of irradiated RFX solutions in phosphate buffer at $\mathrm{pH} 7.4$ do not show appreciable fluoride ion release at least up to $40 \%$ RFX photodegradation. This is consistent with a main photodegradation pathway in which defluorination does not occur. Irradiation of the zwitterionic form leads in fact to decarboxylation, followed by $\mathrm{H}$-atom insertion in place of the carboxylic group [23]. The decarboxylated photoproduct is likely formed via protonation of a carbanionic intermediate, as in the quinolone derivative Nalidixic acid [24]. The photochemical behavior of RFX, quite unusual if compared with that of other drugs of the FLQ family in the zwitterionic form [11,16-19], is consistent with a photoreactivity order as regards the defluorination reaction, which follows the electronegativity order of the substituents in position 8 [18]. Thus the photoreactivity of RFX resembles more that of Ofloxacin than that of Lomefloxacin and Enoxacin [18] (Scheme 3).

Steady state and time resolved emission, triplet state absorption and singlet oxygen production in phosphate buffer at $\mathrm{pH} 7.4$ furtherly outline the differencies between the two photosensitizing drugs. The results indicate that the lowest excited singlet of RFX is a fluorescent, relatively longlived state [25]. The lifetime of $\cong 4.8 \mathrm{~ns}$ is rather long, if compared to that measured in Enoxacin (0.5 ns) [19]. The lowest triplet of RFX is a microsecond state, formed with high quantum yield and efficiently quenched by oxygen with production of singlet oxygen. The parallel oxygen quenching of the photodegradation quantum yields points to the triplet state as precursor of the photodecarboxylation reaction.

These results account for the observed membrane and DNA photosensitization processes (Table 1). UVA induced photodamage by RFX on membranes is significant only in the presence of oxygen, being mediated by singlet oxygen generated by UVA photoexcitation of the drug, whereas the stable photoproduct is not involved in the photosensitization process [23]. The very low damaging action towards membranes in the absence of oxygen is reasonably attributed to the lifetime of the transients involved in the decarboxylation path 


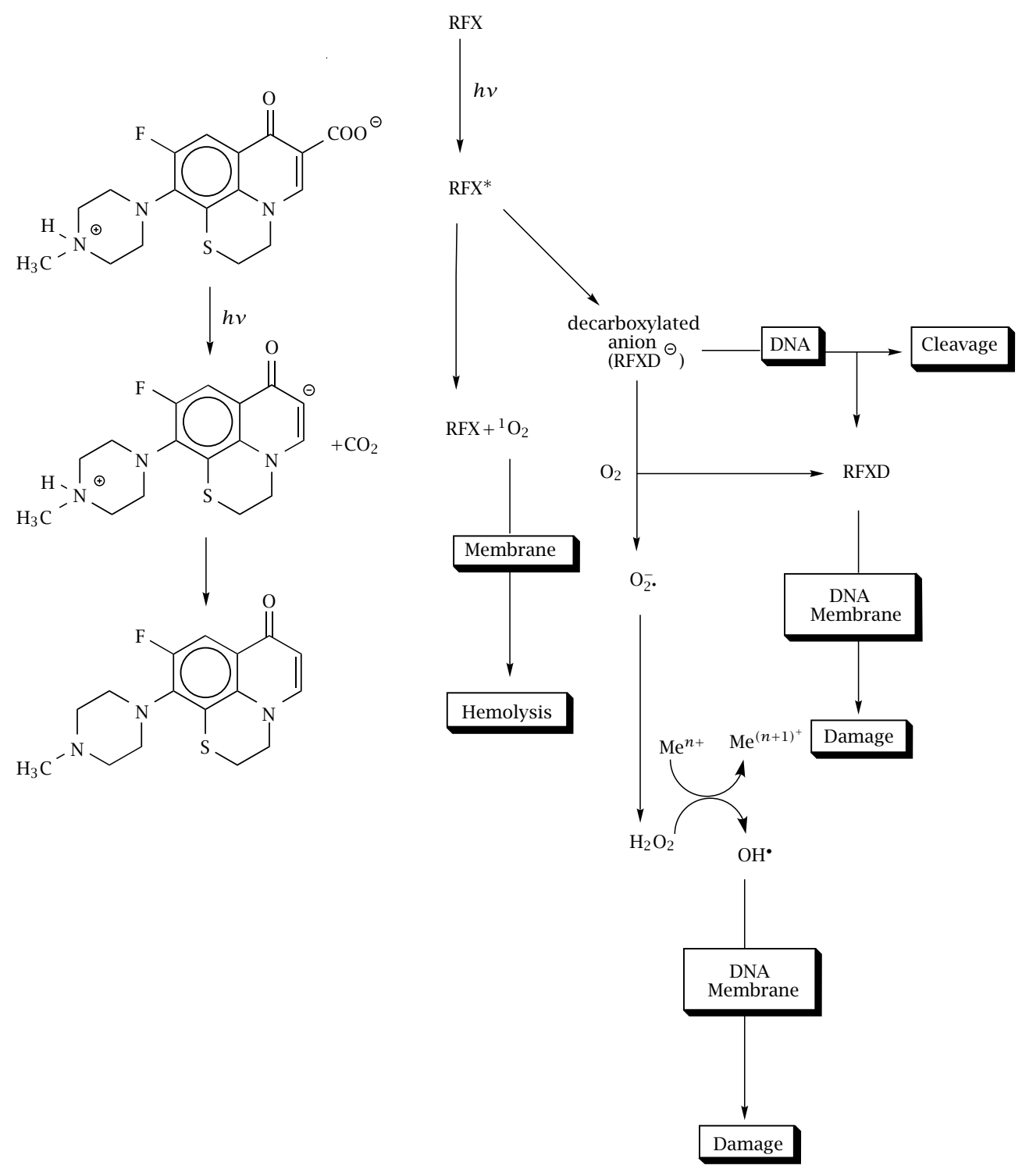

Scheme 3. Rufloxacin photodegradation and photosensitization pathway.

(i.e. the carbanion), short enough to prevent any reaction with membrane components. On the other hand some intermediate (i.e. the triplet state or the carbanion) could in principle undergo electron transfer to oxygen, giving rise to radical species responsible for the damaging activity in aerobic conditions. However, due to the broad and intense absorption and the relatively long lifetime of the precursor triplet no experimental evidence for the occurrence of such processes was obtained by time resolved studies [25].

Table 1. RBC hemolysis and DNA cleavage photoinduced by ENX and RFX. Photohemolysis experiments (recorded $2 \mathrm{~h}$ after the beginning of the irradiation, keeping the samples in the dark): irradiation time $=60 \mathrm{~min} ;[R B C]=3.3 \times 10^{-6} \mathrm{cell} \mathrm{mL}^{-1}$, $[E N X]=5 \times 10^{-5},[R F X]=5 \times 10^{-5}$, temperature $20^{\circ} \mathrm{C}$. Photoinduced sc-DNA cleavage: irradiation time $20 \mathrm{~min},[\mathrm{pBR} 322 \mathrm{bp}$ $3.3 \times 10^{-5},[E N X]=3.3 \times 10^{-5},[R F X]=5 \times 10^{-5}$, temperature $20^{\circ} \mathrm{C}$. Each point is the mean \pm standard of triplicate experiments.

\begin{tabular}{ccccccc}
\hline & \multicolumn{3}{c}{ \% Hemolysis } & \multicolumn{3}{c}{ \%sc-DNA cleavage } \\
\hline \multirow{2}{*}{ ENX } & Air & Nitrogen & Oxygen & Air & Nitrogen & Oxygen \\
& $29 \pm 5$ & $2.0 \pm 0.3$ & $54 \pm 6$ & $32 \pm 3$ & $58 \pm 5$ & $19 \pm 2$ \\
\hline \multirow{2}{*}{ RFX } & Air & Nitrogen & Oxygen & Air & Nitrogen & Oxygen \\
& $45 \pm 4$ & $6 \pm 1$ & $82 \pm 9$ & $21 \pm 2$ & $43 \pm 3$ & $19 \pm 2$ \\
\hline
\end{tabular}


DNA cleavage initiated by RFX follows the trend observed with ENX (Table 1), but the key intermediate involved in the photosensitization processes is different. The high efficiency of DNA cleavage in anaerobic conditions could be in this case attributed to the carbanionic species, able to undergo redox reactions involving base residues on the double helix. Thymine and citosine could be reasonably involved. As a matter of fact, when supercoiled DNA photocleavage is carried out in the presence of increasing concentrations of thymine and cytosine as free bases, the extent of plasmide linearization is reduced, thus supporting a role of these reductable substrates as electron scavengers [26].

\section{ACKNOWLEDGEMENTS}

We thank the Istituto Superiore della Sanità, Progetto Proprietà chimico-fisiche dei medicamenti e loro sicurezza d'uso, and MURST (progetti cofinanziati) for their financial support.

We want to thank also Professor Giuseppe Condorelli for his fruitful suggestions in the preparation of this paper.

\section{REFERENCES}

[1] H. C. Neu, In The 4-Quinolones (G. C. Crumplin, ed.), Springer-Verlag, London, 1990, p. 1.

[2] J. M. Domagala, L. D. Hann, C. L. Heifetz, M. P. Hutt, T. F. Mich, J. P. Sanchez, and M. Solomon, J. Med. Chem. 29 (1986), 394.

[3] R. Izu, J. Gardeazabal, M. Gonzalez, N. Landa, J. A. Raton, and J. L. Diaz Perez, Photodermatol. Photoimmunol. Photomed. 9 (1992), 86.

[4] J. S. Kang, T. H. Kim, K. B. Park, B. H. Chung, and J. I. Youn, Photodermatol. Photoimmunol. Photomed. 9 (1993), 159.

[5] E. D. Shelley and W. B. Shelley, Cutis 42 (1988), 24.

[6] D. Peyramond, F. Biron, S. Tigaud, et al., Rev. Infect. Dis. 11 (1989), no. 5, S1269.

[7] S. T. Nedorost and J. W. E. Dijkstra, Arch. Dermatol. 125 (1989), 433.
[8] E. V. Granowitz, J. Infect. Dis. 160 (1989), 910.

[9] Y. Kurimaji and M. Shono, Contact dermatitis 26 (1992), 5.

[10] G. Condorelli, G. De Guidi, S. Giuffrida, P. Miano, S. Sortino, and A. Velardita, Medicine Biologie Environement 24 (1996), 103.

[11] S. Sortino, G. Condorelli, G. De Guidi, and S. Giuffrida, Photochem. Photobiol. 68 (1998), 652.

[12] J. Ferguson, Photochem. Photobiol. 62 (1995), 954, and references cited therein.

[13] B. E. Johnson, N. Gibbs, and J. K. Ferguson, J. Photochem. Photobiol. B: Biol. 37 (1997), 171.

[14] G. Klecak, F. Urbach, and H. Urwyler, J. Photochem. Photobiol. B: Biol. 37 (1997), 174.

[15] T. Morimura, T. Ohno, H. Matsukura, and Y. Nobuhara, Chem Pharm Bull 43 (1995), no. 6, 1000.

[16] P. Bilski, L. J. Martinez, E. B. Koker, and F. Chignell, Photochem. and Photobiol. 64 (1996), no. 3, 496.

[17] E. Fasani, M. Mella, D. Caccia, S. Tassi, M. Fagnoni, and A. Albini, Chem. Commun (1997), 1329.

[18] E. Fasani, A. Profumo, and A. Albini, Photochem. Photobiol. 68 (1998), 666.

[19] S. Sortino, G. De Guidi, S. Giuffrida, S. Monti, and A. Velardita, Photochem. Photobiol. 67 (1998), 167.

[20] A. W. Girotti, J. P. Thomas, and J. E. Jordan, J. Free Rad. Biol. Med. 1 (1985), 395.

[21] F. E. Evans, J. Deck, and P. C. Howard, Chem. Res. Toxicol. 7 (1994), 52.

[22] G. L. Martinez and C. F. Chignell, Photochem. Photobiol. 65 (1997), 599.

[23] G. Condorelli, G. De Guidi, S. Giuffrida, S. Sortino, R. Chillemi, and S. Sciuto, Photochem. Photobiol accepted for publication, 1999.

[24] F. Vargas, C. Rivas, and R. Machado, B: Biol. 11 (1991), 81.

[25] S. Sortino, G. Marconi, S. Monti, G. De Guidi, and S. Giuffrida, accepted for publication, 1999.

[26] C. Bellecci, Chemistry degree Thesis, 1999, University of Catania, Dept. of Chemistry. 


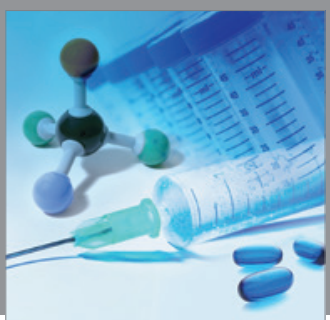

International Journal of

Medicinal Chemistry

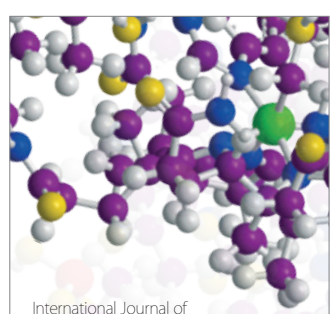

Carbohydrate Chemistry

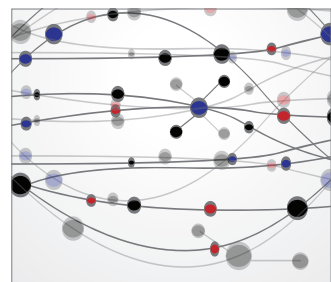

The Scientific World Journal
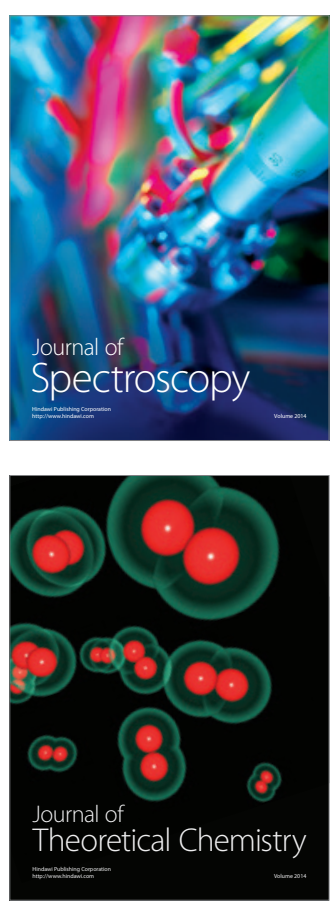
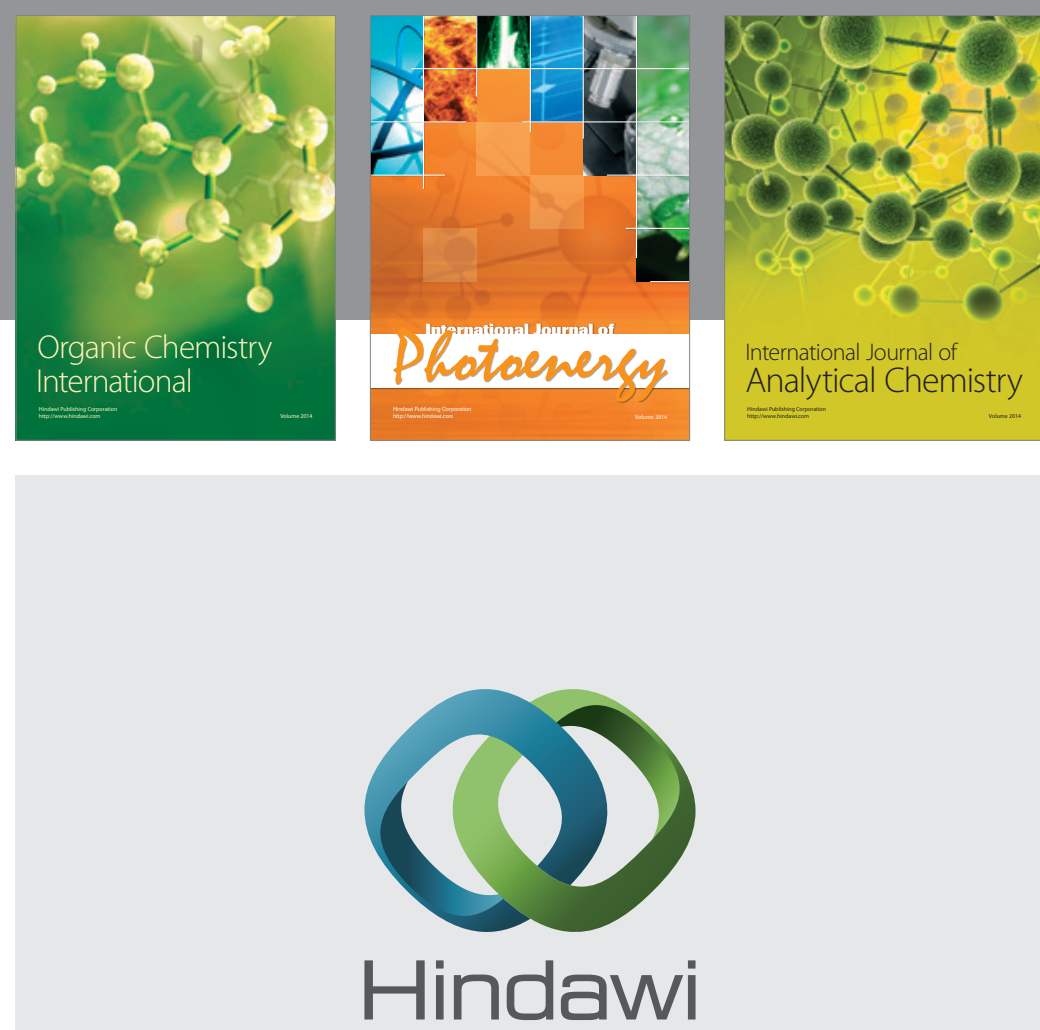

Submit your manuscripts at

http://www.hindawi.com
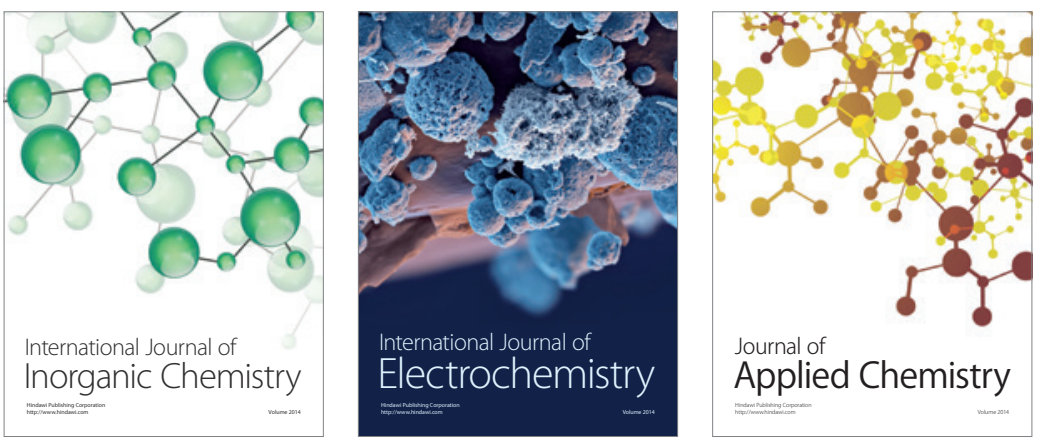

Journal of

Applied Chemistry
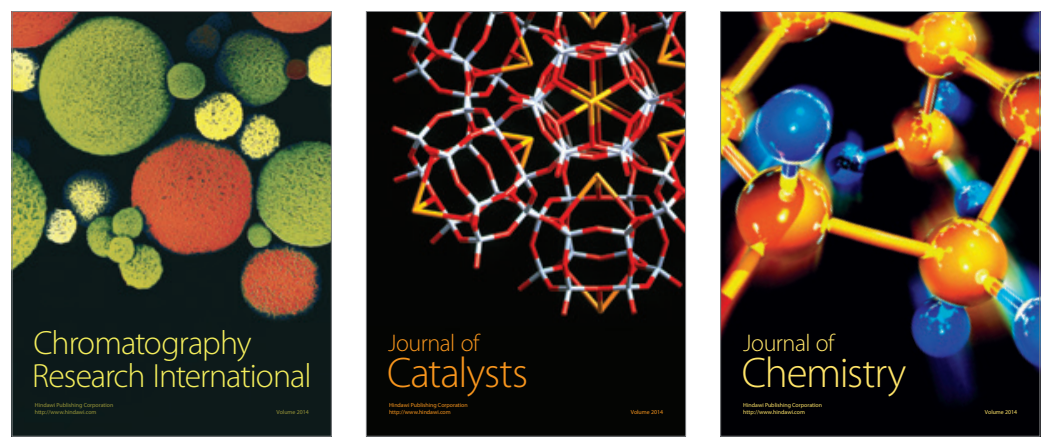
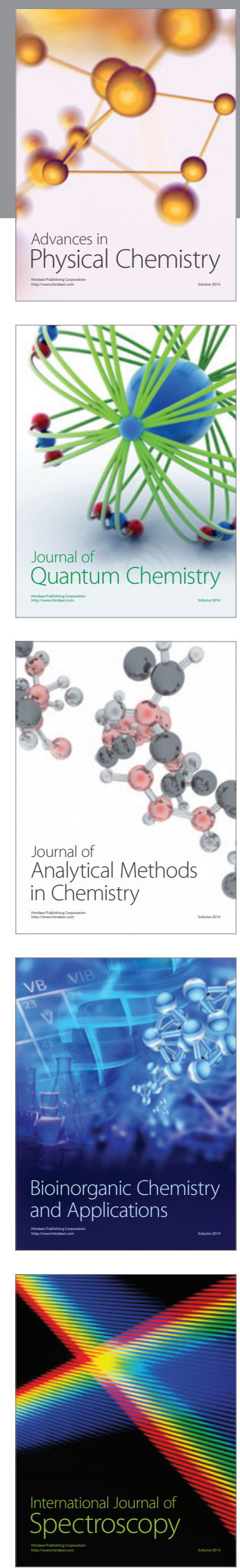